\title{
Características e atributos de Latossolos sob diferentes usos na região Oeste do Estado da Bahia
}

\author{
Ademir Fontana ${ }^{(1)}$, Wenceslau Geraldes Teixeira( ${ }^{(1)}$, Fabiano de Carvalho Balieiro(1), \\ Thayane Pires Alves de Moura ${ }^{(2)}$, Andressa Rosas de Menezes $^{(3)}$ e Camila Ignez Santana ${ }^{(4)}$
}

\begin{abstract}
(1)Embrapa Solos, Rua Jardim Botânico, no 1024, CEP 22460-000 Rio de Janeiro, RJ, Brasil. E-mail: ademir.fontana@embrapa.br, wenceslau.teixeira@embrapa.br, fabiano.balieiro@embrapa.br (2)Universidade Federal do Estado do Rio de Janeiro, Avenida Pasteur, no 458, CEP 22290-255 Rio de Janeiro, RJ, Brasil. E-mail: thayanemoura@outlook.com (3)Universidade Federal Rural do Rio de Janeiro, BR 465, Km 7, CEP 23890-000 Rio de Janeiro, RJ Brasil. E-mail: andressarosas@id.uff.br (4)Universidade Federal do Rio de Janeiro, Avenida Athos da Silveira Ramos, no 274 Cidade Universitária, CEP 21941-902 Rio de Janeiro, RJ, Brasil. E-mail: camilaignez@gmail.com
\end{abstract}

Resumo - O objetivo deste trabalho foi avaliar os efeitos de diferentes usos da terra nas características e nos atributos de Latossolos da região Oeste do Estado da Bahia. Os Latossolos apresentavam texturas com fração areia amplamente predominante, e foram avaliados em áreas de cerrado, algodão, soja e feijão, no Município de Luís Eduardo Magalhães. A caracterização morfológica e a coleta de amostras de solos para avaliação dos atributos físicos e químicos por horizontes foram feitas em minitrincheiras, enquanto a avaliação da condutividade hidráulica saturada foi feita com permeâmetro de Guelph em duas profundidades: $0,0-0,20$ e $0,20-0,40 \mathrm{~m}$. Os Latossolos avaliados, além de uma estrutura maciça, apresentaram horizonte genético adensado, que, sob uso agrícola, torna-se mais compactado, espesso e superficial, e forma torrões quando revolvido. O uso agrícola reduz a condutividade hidráulica saturada dos Latossolos avaliados nas duas camadas, com exceção do cultivo de feijão.

Termos para indexação: Cerrado, camada adensada, compactação de solo, condutividade hidráulica saturada, permeâmetro de Guelph, solos leves.

\section{Characteristics and attributes of Oxisols under different land uses in the western region of the state of Bahia, Brazil}

\begin{abstract}
The objective of this work was to evaluate the effects of different land uses on the characteristics and attributes of Oxisols in the western region of the state of Bahia, Brazil. The Oxisols had textures with largely predominant sand fraction, and they were evaluated in areas of cerrado, cotton, soybean, and common bean in the municipality of Luís Eduardo Magalhães. The morphological characterization and the collection of samples for evaluating soil physical and chemical attributes of horizons were carried out in small trenches, while the evaluation of field saturated hydraulic conductivity was done using the Guelph permeameter at two depths: 0.0 to 0.20 and 0.20 to $0.40 \mathrm{~m}$. The evaluated Oxisols, besides their massive structure, showed a dense genetic horizon, which, under agricultural use, becomes more compacted, thick, and shallow, forming clods when plowed. Agricultural use reduces the saturated hydraulic conductivity of the evaluated Oxisols in both layers, except for common bean cultivation.

Index terms: Cerrado, dense layer, soil compaction, field saturated hydraulic conductivity, Guelph permeameter, light soils.
\end{abstract}

\section{Introdução}

A região Oeste do Estado da Bahia presencia expansão agropecuária e intensificação do uso do solo para o cultivo de grãos, fibras, materiais energéticos, culturas perenes e a agricultura irrigada. A produção agropecuária na região registrou aumento de $70 \%$ em razão do avanço da fronteira agrícola nos últimos dez anos. Na safra de 2013/2014, a área cultivada foi em torno de 2,3 milhões de hectares, com produção agrícola de 7,5 milhões de toneladas, principalmente com os cultivos de soja, algodão, milho e feijão, além da expansão da cafeicultura, plantios de florestas e pastagens (Aiba, 2014).

O relevo, de plano a suave ondulado, os solos responsivos as práticas agrícolas e a boa produtividade das culturas sob agricultura intensiva e convencional estão entre os fatores favoráveis a essa expansão do 
cultivo na região. O preparo periódico do solo é feito com o uso de grades pesadas, arados, escarificadores ou subsoladores e grade niveladora. Em menor escala, há também sistemas com preparo do solo menos intenso, como na integração lavoura-pecuária e no plantio direto, os quais têm sido fomentados por instituições de pesquisa e políticas de estímulo.

A intensificação do uso dos solos nos sistemas agrícolas comumente tem efeito sobre suas características e atributos químicos e físicos, com aparecimento de camadas compactadas limitantes ao desenvolvimento radicular e redução nas taxas de infiltração de água, na aeração e na permeabilidade dos solos. A redução nos espaços entre partículas aumenta a coesão do solo e dificulta seu preparo.

Além disso, tem-se constatado na região, especialmente no Município de Luís Eduardo Magalhães, a presença de uma camada adensada ou compactada, de aspecto maciço coerente, na parte superficial de solos sob cultivo agrícola. Esta camada, ao ser revolvida, aflora na forma de grandes blocos, ou "torrões", que dificultam a realização das operações agrícolas. Ainda são escassas as avaliações dos solos dessa região com a presença das camadas adensadas e entre esses destaca-se Sá et al. (2007) e Marchão et al. (2008). Dessa forma, estudos da estrutura do solo e da transmissão de água entre as camadas do solo podem fornecer informações importantes sobre a origem, distribuição espacial, espessura e profundidade dessas camadas adensadas. Além disso, é importante que se avalie o efeito dos diferentes usos do solo sobre a ocorrência dessas camadas e sobre os atributos físicos e químicos dos solos da região.

O objetivo deste trabalho foi avaliar os efeitos de diferentes usos da terra nas características e atributos de Latossolos no Município de Luís Eduardo Magalhães, no Oeste Baiano.

\section{Material e Métodos}

As avaliações foram realizadas no Município de Luís Eduardo Magalhães, na região Oeste do Estado da Bahia (Figura 1). A região apresenta topografia de plataforma aplainada, com as altitudes entre 700 e 900 m, o relevo plano a suave ondulado, vegetação original de cerrado subcaducifólio (Cerrado "stricto sensu") e formação geológica predominante de arenitos da Formação Urucuia (Levantamento...,
1976). O clima apresenta duas estações climáticas bem definidas: a estação seca e fria, de maio a setembro; e a estação chuvosa e quente, de outubro a abril. As temperaturas médias mínimas e máximas variam entre 20 e $26^{\circ} \mathrm{C}$. A precipitação pluvial anual está entre 1.400 e $1.600 \mathrm{~mm}$, concentrada entre os meses de novembro e março (Batistella et al., 2002).

Foram selecionadas duas áreas sob cerrado para representar a linha de base dos diferentes atributos em estudo, e três outras áreas sob cultivo: uma com algodão sob cultivo convencional; outra com feijão, sob cultivo convencional irrigado por pivô central; e uma última com soja, sob plantio direto. Esses cultivos podem ser considerados os mais comuns sobre Latossolos que têm o cerrado como vegetação original, na região estudada.

Nas áreas de algodão e feijão, as práticas de preparo do solo adotadas foram: gradagem pesada - que serviu como aração - e leve - para nivelamento e destorroamento do solo - ; escarificação; e semeadura. A aplicação de corretivos era feita a cada dois anos, com aplicação anual de fertilizantes, espalhados sobre a superfície do solo e em cobertura, bem como por meio de pulverizações. Essas operações eram feitas com máquinas agrícolas pesadas, que trafegavam nas entrelinhas sem controle de tráfego. $\mathrm{Na}$ área com algodão, ocorreram variações quanto ao uso de trituradores da parte aérea e ao arranque da soca, e o uso do correntão como nivelador, antes da semeadura, era comum. Nesta área, efetuou-se também o cultivo de uma safra de soja, em 2009/2010.

$\mathrm{Na}$ área com soja, cobertura do solo antes do plantio era feita pela vegetação espontânea de timbête, ou capim carrapicho (Cenchrus echinatus), a qual era dessecada antes da semeadura direta sobre a palhada. Este sistema, sem o revolvimento do solo, foi utilizado nos últimos 14 anos, sempre com plantio de soja em semeadura direta, e com apenas dois cultivos de milho nesse período.

As áreas selecionadas eram de Latossolos com predomínio da fração areia na composição granulométrica. A coleta das amostras e as descrições dos solos foram feitas em cada área, em três minitrincheiras de $0,80 \mathrm{~m}$ de profundidade. Os horizontes do solo foram separados quanto às características morfológicas, como tipo de estrutura e consistência do solo seco e úmido (Santos et al., 2013a). 
As minitrincheiras foram distribuídas nas áreas de cultivo e nas áreas de cerrado preservado.

Foram avaliados os seguintes atributos químicos e físicos do solo: $\mathrm{pH}$ em água, cátions trocáveis $\left(\mathrm{Ca}^{2+}+\right.$ $\mathrm{Mg}^{2+}, \mathrm{Al}^{3+}$ ), capacidade de troca catiônica (CTC), carbono orgânico (Corg), ADA, GF, AF, AG, AG/ AF, Ds, VTP análise granulométrica e argila dispersa em água (ADA) (Donagema et al., 2011). Foram calculados o grau de floculação das argilas (GF) e a relação entre areia grossa (AG) e areia fina (AG/AF). Os valores de densidade do solo foram obtidos em amostras indeformadas após coleta em duplicata, em cada horizonte, com anéis de $100 \mathrm{~cm}^{3}$, tendo-se então estimado o volume total de poros (Donagema et al., 2011). Os solos foram classificados segundo o Sistema
Brasileiro de Classificação de Solos (Santos et al., 2013b).

As determinações da condutividade hidráulica saturada $\left(\mathrm{K}_{\mathrm{fs}}\right)$ foram feitas com o permeâmetro de Guelph, com poços escavados nas camadas de $0,0-0,20$ e $0,20-0,40 \mathrm{~m}$ de profundidade, conforme a seguinte equação (Soil Moisture, 2012):

$$
\mathrm{K}_{\mathrm{fs}}=\frac{\mathrm{Q} \times \mathrm{C}}{2 \pi \mathrm{H}^{2}+\pi\left(\mathrm{a}^{*}\right)^{2} \mathrm{C}+2 \pi\left(\mathrm{H} / \mathrm{a}^{*}\right)},
$$

em que $\mathrm{K}_{\mathrm{fs}}$ é a condutividade hidráulica saturada no campo $\left(\mathrm{cm} \mathrm{s}^{-1}\right)$; Q é o valor do fluxo no reservatório $\left(\mathrm{cm} \mathrm{s}^{-1}\right)$; $\mathrm{C}$ é um fator adimensional que depende da estrutura do solo, que, neste estudo, teve o valor 3,0 (Reynolds et al., 2002);H é a carga hidráulica
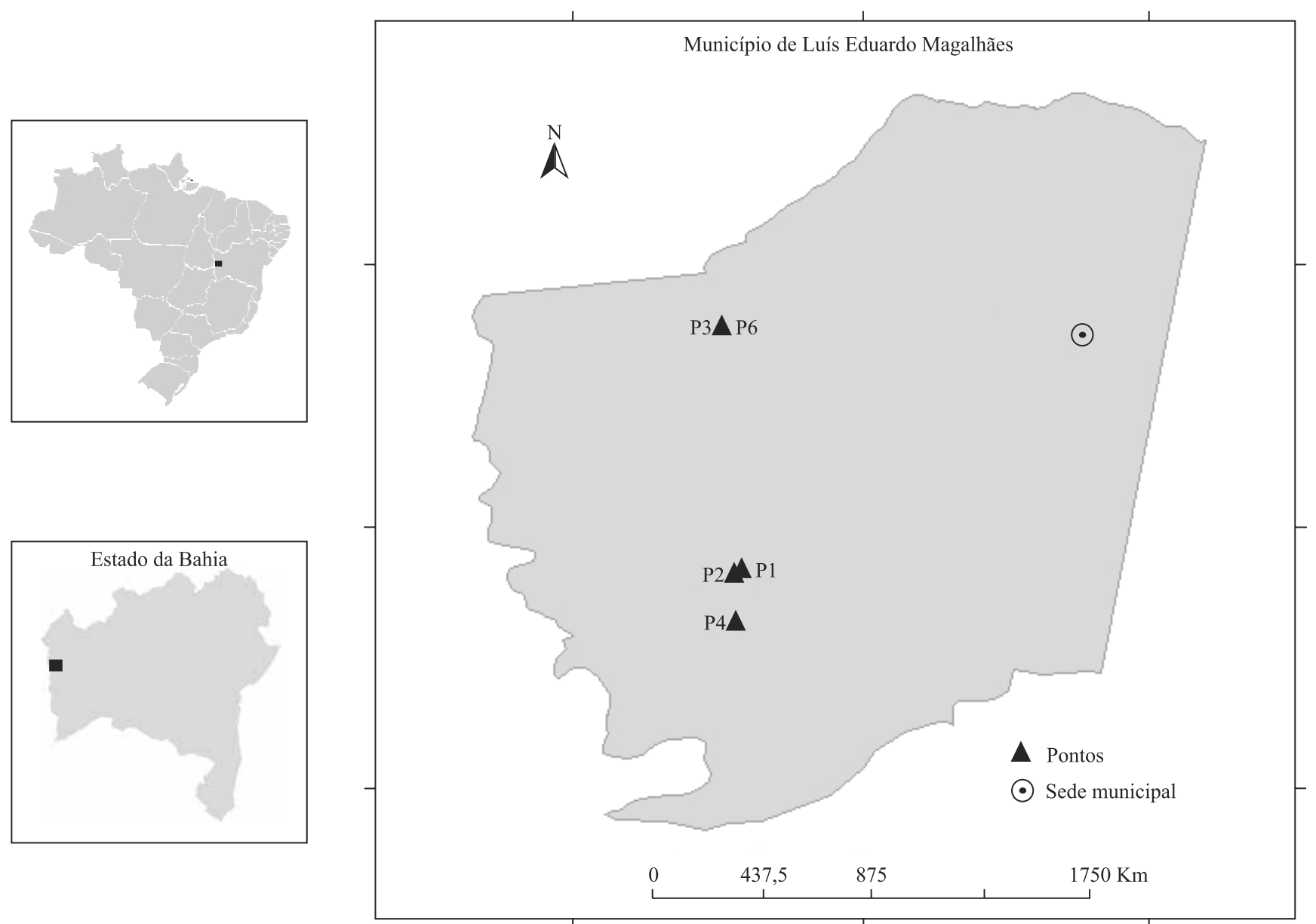

Figura 1. Localização dos pontos estudados no Município de Luís Eduardo Magalhães, Bahia. 
estabelecida no poço de avaliação $(\mathrm{cm})$; e a* é o raio dos poços (capilaridade macroscópica), que tinham o diâmetro de $5 \mathrm{~cm}$.

Os dados de $\mathrm{K}_{\mathrm{fs}}$ apresentaram distribuição log normal e foram transformados pela extração do logaritmo dos valores, adicionados de uma unidade. A apresentação da estatística descritiva dos valores de $\mathrm{K}_{\mathrm{fs}}$ avaliados nos diferentes sistemas e camadas foi feita com o uso de gráficos "boxplot". Os dados de $\mathrm{K}_{\mathrm{fs}}$, após transformação, foram comparados estatisticamente em cada camada, nos diferentes usos, por meio da análise de variância e do teste de comparação de médias HSD Tukey, a 5\% de probabilidade. As análises foram realizadas no Programa R 3.12 (R Core Team, 2015). Foram apresentados os dados originais de $\mathrm{K}_{\mathrm{fs}}$, para permitir a comparação com avaliações de $\mathrm{K}_{\mathrm{fs}}$ feitas em outros estudos.

\section{Resultados e Discussão}

Os solos das áreas estudadas foram classificados como Latossolos Vermelhos, Vermelho-Amarelos e Amarelos, todos distróficos. De maneira geral, as áreas apresentaram atributos físicos e químicos semelhantes, com exceção da área sob cultivo de feijão, que se distinguiu das demais principalmente quanto à composição granulométrica, teores de carbono orgânico $\left(\mathrm{C}_{\text {org }}\right)$ e capacidade de troca catiônica (CTC) (Tabela 1).

Os solos apresentaram predomínio da fração areia na composição granulométrica, com os teores de 643 a $883 \mathrm{~g} \mathrm{~kg}^{-1}$. A participação dessa fração, no entanto, diminuiu em profundidade, com aumento gradativo da fração argila (Tabela 1). Os teores de areia grossa foram ligeiramente superiores aos de areia fina, tendose observado relação areia grossa/areia fina (AG/AF) com valores superiores a 1,09, exceto no cerrado (P5), onde essa relação esteve em torno de 1,00 no horizonte BA ( $0,33 \mathrm{~m}$ de profundidade). Os teores de silte foram os de menor expressão em todos os solos estudados, indício de material de origem mais arenoso - no caso, os arenitos da Formação Urucuia (Levantamento..., 1976) - e de elevada taxa de intemperismo durante a gênese desses solos.

O grau de floculação (GF) variou entre 11 e $29 \%$ nos horizontes mais superficiais (até $0,15 \mathrm{~m}$ ), com ligeiro decréscimo, com valores entre 8 e $17 \%$, nos horizontes imediatamente abaixo e geralmente transicionais $\mathrm{AB}$ ou BA. Nos horizontes subsuperficiais, os valores de
GF foram de duas a quatro vezes (GF entre 60 e 100\%) maiores que nos horizontes superficiais (Tabela 1). Vários fatores podem estar relacionados ao grau de floculação das amostras de solo, especialmente o $\mathrm{pH}$ e o teor de matéria orgânica e de cátions no complexo sortivo do solo; mas chama atenção a ausência de floculação das amostras superficiais nas áreas sob feijão e pivô, com consequente alteração na estrutura do solo, em comparação ao cerrado nativo.

As alterações nos atributos químicos decorrentes das aplicações de calcário e fertilizantes nos horizontes superficiais foram as mais destacadas, nos diferentes sistemas de uso do solo. Nos solos sob cerrado, destacam-se os baixos valores de $\mathrm{pH}$ e de $\mathrm{Ca}^{2+}+\mathrm{Mg}^{2+}$ e altos valores de $\mathrm{Al}^{3+}$ (Tabela 1), enquanto, nas áreas sob cultivo, os valores de $\mathrm{pH}$ estiveram próximos da neutralidade, associados a maiores teores de $\mathrm{Ca}^{2+}+$ $\mathrm{Mg}^{2+}$ e menores de $\mathrm{Al}^{3+}$. Independentemente do uso, todos os atributos apresentam tendência de diminuição em profundidade, exceto para o $\mathrm{pH}$ no solo sob cerrado. Também ficou evidente a concentração do efeito da calagem em superfície, nas áreas de plantio direto, e da distribuição mais homogênea de $\mathrm{Ca}^{2+}+\mathrm{Mg}^{2+}$ no solo sob feijão irrigado.

Os teores de $\mathrm{C}_{\text {org }}$ variaram entre 9,6 e $12,8 \mathrm{~g} \mathrm{~kg}^{-1}$ nos horizontes mais superficiais e seguiram a tendência de diminuírem em profundidade, em todos os usos estudados (Tabela 1). Comparando os diferentes usos às áreas de referência, não é possível observar grandes diferenças nos teores de $\mathrm{C}_{\text {org }}$ do solo em virtude da textura predominantemente arenosa desses Latossolos, que deixa a matéria orgânica naturalmente exposta a decomposição (Zinn et al., 2002; Fialho \& Zinn, 2014). De maneira geral, os teores do $C_{\text {org }}$ estiveram diretamente correlacionados com a CTC, independentemente dos usos e das profundidades avaliadas.

A área com cultivo de feijão apresentou os menores teores de argila, com textura arenosa/média leve, o que destaca o atributo diferencial "psamítico" na classificação do solo. O GF nessa área foi nulo, tanto nos horizontes superficiais quanto nos intermediários, com exceção do horizonte Bw1, que apresentou GF de $67 \%$ e teores de $\mathrm{C}_{\text {org }}$ inferiores aos das demais áreas $\left(3,6 \mathrm{~g} \mathrm{~kg}^{-1}\right)$ (Tabela 1). Associado a essa textura mais grosseira, o uso intensivo de fertilizantes e corretivos, bem como o de irrigação, apresentam-se como fator adicional de degradação ou mineralização da matéria 
orgânica, com reflexos sobre a biodiversidade, CTC e reserva de nutrientes desses solos (Lopes et al., 1982, 2013; Mendes et al., 2012).

$\mathrm{Na}$ avaliação das características morfológicas, nos horizontes mais superficiais dos solos cultivados de forma convencional (algodão e feijão), observouse estrutura do solo em grãos simples; enquanto na área de soja e nas áreas de cerrado, a estrutura foi granular (Tabela 2). O fraco grau de desenvolvimento da estrutura nos horizontes superficiais dos solos, associado a práticas mecânicas de preparo, com revolvimento intensivo do solo, resulta na ocorrência comum de uma camada superficial pulverizada e na forma de grãos simples.

A ocorrência de estrutura maciça, nas áreas de cultivo, se dá logo abaixo dos horizontes superficiais, com formação de horizontes com cimentação aparente (Apx e BAx) (Tabela 2). Nessas áreas, grandes "torrões" são observados na superfície do solo por ocasião do preparo do solo com revolvimento por hastes escarificadoras ou grades pesadas. Esses torrões, no entanto, se tornam muito friáveis quando umedecidos, o que é indicado pelo sufixo "x", que representa um processo de cimentação aparente ou pseudocimentação. Esse fenômeno é caracterizado pela variação na consistência do solo de dura a fortemente dura no solo seco, e friável a muito friável no solo úmido. O manual de descrição e coleta de solos no campo não prevê o uso do sufixo " $\mathrm{x}$ " para os horizontes superficiais A e transicionais AB (Santos et al., 2013a); contudo, propõe-se a adição dele na descrição destes horizontes como forma de qualificar e destacar um processo específico, como a grande variação observada na consistência do solo seco e úmido.

Tabela 1. Atributos químicos e físicos dos horizontes dos Latossolos avaliados sob diferentes usos em Luís Eduardo Magalhães, Bahia ${ }^{(1)}$.

\begin{tabular}{|c|c|c|c|c|c|c|c|c|c|c|c|c|}
\hline \multirow[t]{2}{*}{ Horizonte } & \multirow{2}{*}{$\begin{array}{l}\text { Profundidade } \\
(\mathrm{cm})\end{array}$} & AG & $\mathrm{AF}$ & Silte & Argila & \multirow{2}{*}{$\begin{array}{l}\text { GF } \\
(\%)\end{array}$} & \multirow[t]{2}{*}{$\mathrm{AG} / \mathrm{AF}$} & \multirow{2}{*}{$\begin{array}{c}\mathrm{pH} \\
\mathrm{H}_{2} \mathrm{O} \\
\end{array}$} & $\mathrm{Ca}^{2+}+\mathrm{Mg}^{2+}$ & $\mathrm{Al}^{3+}$ & СTC & \multirow{2}{*}{$\begin{array}{c}\mathrm{C}_{\text {org }} \\
\left(\mathrm{g} \mathrm{kg}^{-1}\right)\end{array}$} \\
\hline & & \multicolumn{4}{|c|}{----------- $\left(\mathrm{g} \mathrm{kg}^{-1}\right)$------------- } & & & & \multicolumn{3}{|c|}{---------- $\left(\mathrm{cmolc} \mathrm{kg}^{-1}\right)$---------- } & \\
\hline & \multicolumn{12}{|c|}{ P1, Cerrado; Latossolo Amarelo distrófico típico (textura média) } \\
\hline A1 & $0-6$ & 470 & 376 & 13 & 141 & 29 & 1,25 & 4,1 & 1,0 & 1,0 & 5,4 & 9,7 \\
\hline $\mathrm{A} 2$ & $6-16$ & 420 & 382 & 17 & 181 & 11 & 1,09 & 4,2 & 0,7 & 0,7 & 3,3 & 4,7 \\
\hline$A B x$ & $16-34$ & 422 & 365 & 12 & 201 & 10 & 1,15 & 4,3 & 0,8 & 0,4 & 3,1 & 4,0 \\
\hline \multirow[t]{2}{*}{ Bw2 } & $60-90$ & 376 & 340 & 23 & 261 & 77 & 1,10 & 5,0 & 0,7 & 0,2 & 1,7 & 2,5 \\
\hline & \multicolumn{12}{|c|}{ P2, Algodão; Latossolo Vermelho-Amarelo distrófico típico (textura média) } \\
\hline Ap & $0-5 / 5-25$ & 464 & 304 & 28 & 204 & 21 & 1,53 & 6,4 & 3,2 & 0,1 & 6,3 & 10,0 \\
\hline Apx & $5-25 / 35$ & 464 & 304 & 30 & 202 & 10 & 1,53 & 5,8 & 2,5 & 0,0 & 5,6 & 6,2 \\
\hline BAx & $35-60$ & 424 & 310 & 24 & 242 & 8 & 1,37 & 5,3 & 0,6 & 0,1 & 3,5 & 4,3 \\
\hline \multirow[t]{2}{*}{ Bw1 } & $60-80$ & 416 & 262 & 18 & 304 & 60 & 1,59 & 4,8 & 0,6 & 0,2 & 3,3 & 3,1 \\
\hline & \multicolumn{12}{|c|}{ P3, Soja; Latossolo Vermelho distrófico típico (textura média) } \\
\hline Ap & $0-10 / 15$ & 428 & 303 & 47 & 222 & 18 & 1,37 & 6,3 & 3,8 & 0,0 & 6,1 & 9,6 \\
\hline Apx & $10 / 15-26$ & 401 & 329 & 28 & 242 & 17 & 1,59 & 4,8 & 0,9 & 0,3 & 4,3 & 5,8 \\
\hline BA & $26-46$ & 381 & 333 & 44 & 242 & 17 & 1,35 & 4,6 & 0,7 & 0,3 & 3,5 & 3,9 \\
\hline Bw1 & $46-62$ & 351 & 307 & 59 & 283 & 100 & 1,41 & 5,0 & 0,7 & 0,1 & 2,9 & 2,9 \\
\hline \multirow[t]{2}{*}{ Bw2 } & $62-80$ & 347 & 325 & 46 & 282 & 100 & 1,22 & 4,6 & 0,7 & 0,2 & 3,3 & 2,9 \\
\hline & \multicolumn{12}{|c|}{ P4, Feijão; Latossolo Vermelho-Amarelo psamítico (textura média) } \\
\hline Ap & $0-14$ & 562 & 321 & 17 & 100 & 0 & 1,75 & 6,2 & 2,7 & 0,0 & 3,0 & 3,6 \\
\hline Apx & $14-28$ & 532 & 321 & 27 & 120 & 0 & 1,65 & 5,5 & 1,6 & 0,0 & 2,0 & 2,4 \\
\hline BA & $28-44$ & 472 & 339 & 8 & 181 & 0 & 1,39 & 4,9 & 1,3 & 0,0 & 2,1 & 2,1 \\
\hline \multirow[t]{2}{*}{ Bw1 } & 44-70 & 436 & 346 & 37 & 181 & 67 & 1,26 & 5,1 & 1,0 & 0,0 & 1,4 & 2,0 \\
\hline & \multicolumn{12}{|c|}{ P5, Cerrado; Latossolo Vermelho distrófico típico (textura média) } \\
\hline A1 & $0-6$ & 421 & 302 & 34 & 243 & 25 & 1,39 & 4,8 & 1,2 & 0,6 & 7,8 & 12,8 \\
\hline A2 & $6-20$ & 402 & 319 & 37 & 242 & 17 & 1,26 & 4,8 & 0,5 & 0,5 & 5,0 & 7,5 \\
\hline $\mathrm{AB}$ & $20-33$ & 379 & 347 & 32 & 242 & 8 & 1,09 & 5,1 & 0,4 & 0,3 & 3,5 & 5,4 \\
\hline BA & $33-54$ & 321 & 325 & 51 & 303 & 14 & 0,99 & 5,0 & 0,5 & 0,2 & 3,0 & 4,6 \\
\hline Bw1 & $54-85$ & 323 & 325 & 49 & 303 & 100 & 0,99 & 5,1 & 0,5 & 0,1 & 2,8 & 3,9 \\
\hline
\end{tabular}

(1) AG, areia grossa; AF, areia fina; GF, grau de floculação; CTC, capacidade de troca catiônica a pH 7,0; e C ${ }_{\text {org }}$, carbono orgânico. 
Os solos sob vegetação de cerrado (P1 e P5) diferenciaram-se dos solos sob cultivo, basicamente, quanto à consistência do solo seco, que sob cerrado foi ligeiramente dura na superfície; já no solo sob cultivo, houve horizontes caracterizados como extremamente duros e duros (Tabela 2). O aumento na coesão dos solos aumenta a resistência à penetração e promove fraca organização estrutural, com pouca ou nenhuma superfície de fraqueza, o que confere o aspecto maciço da estrutura e a tendência de formação de blocos pelo preparo (Santos et al., 2013a, 2013b). Neste estudo, a resistência dos solos à penetração (RP) apresentouse acima do limite máximo de medida do aparelho $(>2.000 \mathrm{kPa})$, o que inviabilizou sua determinação precisa.

Os valores de densidade do solo (Ds) evidenciaram os efeitos dos diferentes usos do solo, sobretudo com o aumento nos seus valores nos horizontes caracterizados como compactados (Apx e BAx), que foram maiores ou iguais a $1,64 \mathrm{~g} \mathrm{~m}^{-3}$ (Tabela 2). Como reflexo do aumento da Ds, o volume total de poros (VTP) diminuiu e atingiu valores entre 35 e $40 \%$. Notadamente nos solos sob cerrado, os horizontes transicionais ou subsuperficiais indicaram ligeiro aumento dos valores de Ds; contudo, em menor magnitude que nos solos cultivados. Esse aumento da Ds, mesmo em áreas sem tráfego de máquinas, indica a presença de horizonte genético coeso em condições originais. A evidência de adensamento pedogenético é comumente relacionada a Latossolos desenvolvidos em ambiente de Tabuleiro Costeiro (Giarola et al., 2001; Moreau et al., 2006; Silva \& Carvalho, 2007; Corrêa et al., 2008; Lima Neto et al., 2009; Dantas et al., 2014).

Mesmo reconhecendo que a composição granulométrica das áreas podem influenciar os valores de Ds, os horizontes superficiais com os menores valores desse atributo foram os dos Latossolos sob cerrado (P5) e sob cultivo de algodão, que foram

Tabela 2. Estrutura e consistência dos horizontes de Latossolos avaliados sob diferentes usos em Luís Eduardo Magalhães, Bahia.

\begin{tabular}{|c|c|c|c|c|c|}
\hline Horizonte & $\begin{array}{l}\text { Estrutura } \\
\text { (tipo) }\end{array}$ & $\begin{array}{l}\text { Consistência } \\
(\mathrm{seco})\end{array}$ & $\begin{array}{l}\text { Consistência } \\
\text { (úmido) }\end{array}$ & $\begin{array}{c}\mathrm{Ds}^{(1)} \\
\left(\mathrm{Mg} \mathrm{m}^{-3}\right) \\
\end{array}$ & $\begin{array}{c}\mathrm{VTP}^{(2)} \\
(\%) \\
\end{array}$ \\
\hline \multicolumn{6}{|c|}{ P1, Cerrado; Latossolo Amarelo distrófico típico (textura média) } \\
\hline A1 & Granular e grãos simples & Ligeiramente dura & Friável & 1,33 & 49 \\
\hline A2 & Granular & Ligeiramente dura & Muito friável & 1,45 & 45 \\
\hline $\mathrm{ABx}$ & Bloco subangular qsd granular & Dura & Muito friável & 1,51 & 42 \\
\hline Bw2 & Bloco subangular qsd granular & Ligeiramente dura & Friável & 1,50 & 43 \\
\hline \multicolumn{6}{|c|}{ P2, Algodão; Latossolo Vermelho-Amarelo distrófico típico (textura média) } \\
\hline Ap & Grãos simples & Solta & Solta & 1,23 & 53 \\
\hline Apx & Maciça & Extremamente dura & Muito friável & 1,64 & 38 \\
\hline BAx & Maciça & Muito dura & Friável & 1,67 & 35 \\
\hline Bw1 & Bloco subangular qsd granular & Ligeiramente dura & Muito friável & 1,56 & 40 \\
\hline \multicolumn{6}{|c|}{ P3, Soja; Latossolo Vermelho distrófico típico (textura média) } \\
\hline Ap & Granular & Ligeiramente dura & Friável & 1,32 & 49 \\
\hline Apx & Maciça & Muito dura & Friável & 1,64 & 39 \\
\hline BA & Bloco subangular qsd granular & Ligeiramente dura & Muito friável & 1,44 & 46 \\
\hline Bw1 & Bloco subangular qsd granular & Ligeiramente dura & Muito friável & 1,46 & 47 \\
\hline Bw2 & Bloco subangular qsd granular & Macia & Muito friável & 1,35 & 48 \\
\hline \multicolumn{6}{|c|}{ P4, Feijão; Latossolo Vermelho-Amarelo psamítico (textura média) } \\
\hline Ap & Grãos simples & Solta & Solta & 1,33 & 51 \\
\hline Apx & Maciça & Muito dura & Muito friável & 1,67 & 40 \\
\hline BA & Bloco subangular & Ligeiramente dura & Friável & 1,64 & 40 \\
\hline Bw1 & Bloco subangular qsd granular & Ligeiramente dura & Friável & nd & nd \\
\hline \multicolumn{6}{|c|}{ P5, Cerrado; Latossolo Vermelho distrófico típico (textura média) } \\
\hline A1 & Granular & Ligeiramente dura & Muito friável & 1,17 & 56 \\
\hline A2 & Granular & Ligeiramente dura & Muito friável & 1,25 & 54 \\
\hline $\mathrm{AB}$ & Granular/Bloco subangular & Ligeiramente dura & Muito friável & 1,29 & 52 \\
\hline BA & Granular/Bloco subangular & Ligeiramente dura & Muito friável & 1,45 & 48 \\
\hline Bw1 & Granular & Ligeiramente dura & Muito friável & 1,41 & 48 \\
\hline
\end{tabular}

${ }^{(1)} \mathrm{Ds}$, densidade do solo. ${ }^{(2)}$ VTP, volume total de poros. qsd, que se desfaz. nd, não determinado. 
inferiores aos observados sob cultivo de feijão, soja e sob a área P1 de cerrado. Aumento nos valores de Ds no horizonte $\mathrm{AB}(0,30-0,50 \mathrm{~m}$ de profundidade) já foi relatado em levantamento de Latossolos na região do Cerrado (Levantamento..., 1976). Freitas et al. (2014) também observaram aumento na Ds nos horizontes transicionais de Latossolos (entre 0,19 e 0,68 m de profundidade), o qual se assemelhou ao observado na área $\mathrm{P} 1$ de cerrado, no presente estudo. No que se refere a solos cultivados, Marchão et al. (2008) observaram menores valores de Ds para solos sob cerrado e cultivo de algodão, em comparação a solos sob cultivo de soja e feijão, na camada de 0 a $0,10 \mathrm{~m}$ de profundidade.

$\mathrm{O}$ aumento da Ds nas áreas sem tráfego de máquinas (áreas sob cerrado) ocorreu abaixo de $0,30 \mathrm{~m}$ de profundidade, ao passo que, sob cultivo, além de mais espessa e densa, essa camada adensada ocorreu mais próxima à superfície. Nos solos das áreas cultivadas, adiciona-se ao adensamento genético o processo de compactação ocasionado pelas operações de preparo do solo e tráfego de máquinas agrícolas. Dias Junior \& Pierce (1996) apresentam uma revisão pertinente sobre o processo de compactação do solo, enquanto

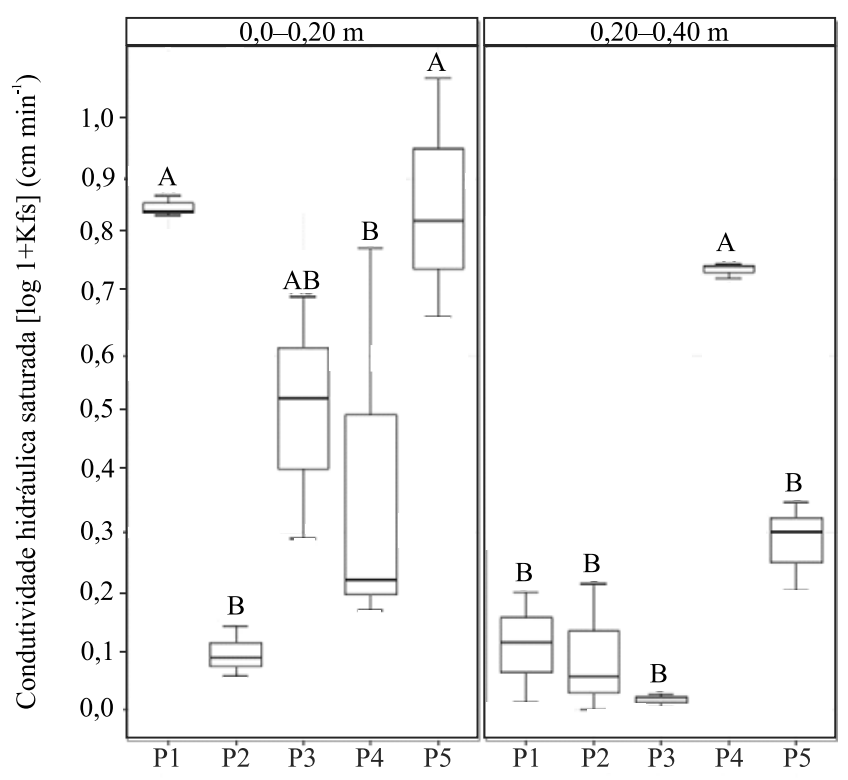

Figura 2. Condutividade hidráulica saturada dos solos $\left(\mathrm{K}_{\mathrm{fs}}\right)$, avaliada em duas camadas, em Latossolos sob diferentes usos em Luís Eduardo Magalhães, Bahia. Médias seguidas de letras iguais, na mesma camada, não diferem pelo teste de Tukey, a 1\% de probabilidade. P1, Cerrado; P2, algodão; P3, soja; P4, feijão; e P5, Cerrado.
Richart et al. (2005) discutem as causas e os efeitos da compactação.

Os valores de condutividade hidráulica saturada de campo $\left(\mathrm{K}_{\mathrm{fs}}\right)$ apresentaram grande variabilidade, o que é ilustrado pelo tamanho dos boxes e das barras (desvio-padrão), em especial na área sob cultivo de feijão (Figura 2). Os valores de $\mathrm{K}_{\mathrm{fs}}$ foram significativamente menores na superfície dos solos sob algodão e feijão, enquanto a área sob plantio direto de soja apresentou valores intermediários, e as áreas de cerrado, os maiores valores.

Nas camadas superficiais das áreas de cerrado, os valores da $\mathrm{K}_{\mathrm{fs}}$ foram de 6,13 e $6,73 \mathrm{~cm} \mathrm{~min}^{-1}$ (Tabela 3), os quais indicam ocorrência de meios porosos com alta permeabilidade. Na camada de 0,20 a $0,40 \mathrm{~m}$, os valores estiveram entre 0,04 e $0,94 \mathrm{~cm} \mathrm{~min}^{-1}$, com exceção da área sob cultivo de feijão $\left(4,58 \mathrm{~cm} \mathrm{~min}^{-1}\right)$, que são considerados valores de permeabilidade intermediários (Reynolds et al., 2002).

Constatou-se a existência de um gradiente de $\mathrm{K}_{\mathrm{fs}}$ entre as camadas, com exceção para o Latossolo Vermelho-Amarelo sob cultivo de algodão, onde os valores do atributo foram muito baixos em ambas as camadas avaliadas, indício de uma degradação bastante acentuada da estrutura do solo. Nas áreas sob cerrado e sob cultivo de soja, a $\mathrm{K}_{\mathrm{fs}}$ diminuiu em profundidade, enquanto ocorreu o oposto no solo sob feijão. A maior variação nos valores de $\mathrm{K}_{\mathrm{fs}}$ entre camadas

Tabela 3. Condutividade hidráulica saturada média, avaliada em duas camadas, em Latossolos sob diferentes usos em Luís Eduardo Magalhães, Bahia.

\begin{tabular}{|c|c|c|c|}
\hline $\begin{array}{l}\text { Camada } \\
(\mathrm{m})\end{array}$ & Horizonte & $\begin{array}{c}\text { Condutividade } \\
\text { hidraúlica saturada } \\
\left.(\mathrm{cm} \mathrm{min})^{-1}\right)\end{array}$ & $\begin{array}{c}\text { Desvio-padrão } \\
\text { da média }\end{array}$ \\
\hline & \multicolumn{3}{|c|}{ P1, Cerrado; Latossolo Amarelo distrófico típico } \\
\hline $0,00-0,20$ & A2 & 6,13 & 0,29 \\
\hline \multirow[t]{2}{*}{$0,20-0,40$} & $\mathrm{ABx}$ & 0,30 & 0,28 \\
\hline & \multicolumn{3}{|c|}{ P2, Algodão; Latossolo Vermelho-Amarelo distrófico típico } \\
\hline $0,00-0,20$ & Apx & 0,25 & 0,12 \\
\hline \multirow[t]{2}{*}{$0,20-0,40$} & BAx & 0,26 & 0,33 \\
\hline & \multicolumn{3}{|c|}{ P3, Soja; Latossolo Vermelho distrófico típico } \\
\hline $0,00-0,20$ & Apx & 2,44 & 1,54 \\
\hline \multirow[t]{2}{*}{$0,20-0,40$} & BA & 0,04 & 0,03 \\
\hline & \multicolumn{3}{|c|}{ P4, Feijão; Latossolo Vermelho-Amarelo distrófico psamíticc } \\
\hline $0,00-0,20$ & Apx & 2,06 & 2,59 \\
\hline \multirow[t]{2}{*}{$0,20-0,40$} & BA & 4,58 & 0,16 \\
\hline & \multicolumn{3}{|c|}{ P5, Cerrado; Latossolo Vermelho distrófico típico } \\
\hline $0,00-0,20$ & A2 & 6,73 & 3,69 \\
\hline $0,20-0,40$ & $\mathrm{BA}$ & 0,94 & 0,33 \\
\hline
\end{tabular}

Pesq. agropec. bras., Brasília, v.51, n.9, p.1457-1465, set. 2016 DOI: 10.1590/S0100-204X2016000900044 
ocorreu nos solos sob cerrado (Tabela 3). De forma geral, observou-se redução acentuada nos valores da transmissão de água das camadas superficiais para as subsuperficiais do solo, mesmo nas áreas naturais, sem tráfego de máquinas. Esse resultado indica a presença de horizonte coeso.

Os valores da $\mathrm{K}_{\mathrm{fs}}$ das duas camadas avaliadas corroboram, em parte, os dados obtidos para Ds, VTP, consistência e coesão nos horizontes correspondentes. Dessa forma, os menores valores da $\mathrm{K}_{\mathrm{fs}}$ na camada superficial, até $0,20 \mathrm{~m}$ de profundidade, para os solos sob cultivo, estiveram relacionados a maiores valores da Ds e à estrutura maciça e fortemente coesa.

O aumento da coesão do solo provocado pelas práticas de cultivo demanda um conhecimento mais efetivo da umidade do solo e de seus limites de plasticidade, especialmente para o uso de grades aradoras e niveladoras, escarificadores e subsoladores, que são ineficazes na quebra ou afrouxamento das camadas compactadas com o solo seco, quando há formação de torrões na superfície dos solos, que dificultam o plantio. Acima do limite de plasticidade, com o solo úmido e muito friável, o preparo também é ineficaz, pois neste caso ocorre o simples corte do solo, sem a quebra das camadas compactadas.

Os resultados do presente estudo, especialmente quanto à camada coesa existente nos Latossolos sem uso agrícola na região, apontam para restrições ao cultivo intensivo desses solos, uma vez que o tráfego intenso de máquinas pode agravar os efeitos nocivos dessa camada, pela compactação do solo, o que teria forte reflexo sobre a produtividade agrícola, especialmente em anos com deficiência hídrica. Além disso, a intensificação da restrição física ao uso dos Latossolos com camada genética coesa, pela compactação, pode levar ao estreitamento do calendário agrícola na região.

\section{Conclusões}

1. Os Latossolos sob vegetação de cerrado, avaliados na região do Oeste da Bahia, apresentam horizonte subsuperficial adensado, o qual pode tornar-se ainda mais compacto, espesso e superficial com o uso agrícola.

2. Os horizontes compactados dos Latossolos sob o uso agrícola apresentam estrutura maciça, com consistência seca muito dura ou extremamente dura, e maiores valores de densidade do solo, o que leva ao desenvolvimento de grandes torrões na superfície dos solos quando estes são revolvidos com baixa umidade.

3. A condutividade hidráulica saturada diminui em profundidade, em todos os usos, exceto o com feijão irrigado; e os Latossolos sob uso agrícola apresentaram menor condutividade hidráulica saturada que os sob cerrado, na camada superficial do solo.

\section{Agradecimentos}

Ao Conselho Nacional de Desenvolvimento Científico e Tecnológico (CNPq), pelo financiamento no Projeto Universal No 478003/2013-7 e pela bolsa de Iniciação Científica à quarta autora; ao engenheiroagrônomo Ingbert Dowich, consultor técnico da Associação de Plantio Direto no Cerrado (APDC), e à Círculo Verde, Assessoria Agronômica \& Pesquisa, pelo apoio logístico, indicação de áreas, avaliações em campo e coleta das amostras; e às fazendas Marechal Rondon e Alvorada, pela recepção e disponibilização das áreas para as avaliações e amostragem dos solos.

\section{Referências}

AIBA. Associação de Agricultores e Irrigantes da Bahia. Anuário da região oeste da Bahia: safra 2013/14. 2014. Disponível em: $<$ http://aiba.org.br/anuario/>. Acesso em: 28 jul. 2015.

BATISTELLA, M.; GUIMARÃES, M.; MIRANDA, E.E. de; VIEIRA, H.R.; VALLADARES, G.S.; MANGABEIRA, J.A. de C.; ASSIS, M.C. de. Monitoramento da expansão agropecuária na região oeste da Bahia. Campinas: Embrapa Monitoramento por Satélite, 2002. 40p. (Embrapa Monitoramento por Satélite. Documentos, 20).

CORRÊA, M.M; KER, J.C.; BARRÓN, V.; TORRENT, J.; CURI, N.; TORRES, T.C.P. Caracterização física, química, mineralógica e micromorfológica de horizontes coesos e fragipãs de solos vermelhos e amarelos do ambiente Tabuleiros Costeiros. Revista Brasileira de Ciência do Solo, v.32, p.297-313, 2008. DOI: 10.1590/S0100-06832008000100028.

DANTAS, J.S.; MARQUES JÚNIOR, J.; MARTINS FILHO, M.V.; RESENDE, J.M. do A.; CAMARGO, L.A.; BARBOSA, R.S. Gênese de solos coesos do leste maranhense: relação solopaisagem. Revista Brasileira de Ciência do Solo, v.38, p.10391050, 2014. DOI: 10.1590/S0100-06832014000400001.

DIAS JUNIOR, M. de S.; PIERCE, F.J. O processo de compactação do solo e sua modelagem. Revista Brasileira de Ciência do Solo, v.20, p.175-182, 1996.

DONAGEMA, G.K.; CAMPOS, D.V.B. de; CALDERANO, S.B. TEIXEIRA, W.G.; VIANA, J.H.M (Org.). Manual de métodos de análise de solos. 2.ed. rev. Rio de Janeiro: Embrapa Solos, 2011. 230p. (Embrapa Solos. Documentos, 132). 
FIALHO, R.C.; ZINN, Y.L. Changes in soil organic carbon under eucalyptus plantations in Brazil: a comparative analysis. Land Degradation and Development, v.25, p.428-437, 2014. DOI: 10.1002/ldr.2158.

FREITAS, P.L. de; POLIDORO, J.C.; SANTOS, H.G. dos; PRADO, R.B.; CALDERANO, S.B.; GREGORIS, G.; MANZATTO, C.V.; DOWICH, I.; BERNARDI, A.C. de C. Identificação e caracterização físico-química de Latossolos de textura arenosa e média da região oeste da Bahia. Cadernos de Geociências, v.11, p.82-92, 2014.

GIAROLA; N.F.B.; SILVA, A.P.; TORMENA, C.; SOUZA, L.S.; RIBEIRO, L.P. Similaridades entre o caráter coeso dos solos e o comportamento hardsetting: estudo de caso. Revista Brasileira de Ciência do Solo, v.25, p.239-247, 2001. DOI: 10.1590/S010006832001000100026.

LEVANTAMENTO exploratório - reconhecimento de solos da margem esquerda do Rio São Francisco Estado da Bahia. Recife: Embrapa-SNLCS, 1976. 404p. (EMBRAPA-SNLCS. Boletim Técnico, 38; SUDENE-DRN. Série Recursos de Solos, 7).

LIMA NETO, J. de A.; RIBERO, M.R.; CORRÊA, M.M.; SOUZA JÚNIOR, V.S. de; LIMA, J.F.W.F.; FERREIRA, R.F. de A. e L. Caracterização e gênese do caráter coeso em Latossolos Amarelos e Argissolos dos Tabuleiros Costeiros do estado de Alagoas. Revista Brasileira de Ciência do Solo, v.33, p.10011011, 2009. DOI: 10.1590/S0100-06832009000400024.

LOPES, A.C. de C.; SOUSA,D.M.G. de; CHAER, G.M.; REIS JUNIOR, F.B. dos; GOEDERT, W.J.; MENDES, I. de C. Interpretation of microbial soil indicators as a function of crop yield and organic carbon. Soil Science Society of America Journal, v.77, p.461-472, 2013. DOI: 10.2136/sssaj2012.0191.

LOPES, A.S. Solos sob Cerrado: características, propriedade e manejo. 2.ed. Piracicaba: Associação Brasileira para Pesquisa da Potassa e do Fosfato, 1982. 162p.

MARCHÃO, R.L.; VILELA, L.; SANTOS JUNIOR, J. de D.G.; SÁ, M.A.C. de; BERGAMASCHI, L.C.; BORTONCELLO, L.R. Impacto de sistemas agrícolas nos atributos físicos, químicos e macrofauna num Latossolo do oeste baiano. Planaltina: Embrapa Cerrados, 2008. 30p. (Embrapa Cerrados. Boletim de pesquisa e desenvolvimento, 228).

MENDES, I. de C.; FERNANDES, M.F.; CHAER, G.M.; REIS JUNIOR, F.B. dos. Biological functioning of Brazilian Cerrado soils under different vegetation types. Plant and Soil, v.359, p.183-195, 2012. DOI: 10.1007/s11104-012-1195-6.
MOREAU, A.M.S. dos S.; COSTA, L.M. da; KER, J.C.; GOMES, F.H. Gênese de horizonte coeso, fragipã e duripã em solos do Tabuleiro Costeiro do sul da Bahia. Revista Brasileira de Ciência do Solo, v.33, p.1021-1030, 2006.

R CORE TEAM. R: A language and environment for statistical computing. Vienna: R Foundation for Statistical Computing, 2015.

REYNOLDS, W.D.; ELRICK, D.E.; YOUNGS, E.G.; AMOOZEGAR, A.; BOOLTINK, H.W.G.; BOUMA. J. Saturated and field-saturated water flow parameters: In: DANE, J.H.; TOPP, C. (Ed.). Methods of soil analysis: part 4: physical methods, Madison: Soil Science Society of America, 2002. p.797-878.

RICHART, A.; TAVARES FILHO, J.; BRITO, O.R.; LLANILLO, R.F.; FERREIRA, R. Compactação do solo: causas e efeitos. Semina: Ciências Agrárias, v.26, p.321-344, 2005. DOI: 10.5433/1679-0359.2005v26n3p321.

SÁ, M.A.C. de; SHIRATSUCHI, L.S.; FRANZ, C.A.B.; SANTOS JUNIOR, J. de D.G. dos. Compactação do solo e produtividade da cultura da soja em área irrigada no Cerrado. Planaltina: Embrapa Cerrados, 2007. 31p. (Embrapa Cerrados. Boletim de pesquisa e desenvolvimento, 177).

SANTOS, H.G. dos; JACOMINE, P.K.T.; ANJOS, L.H.C. dos; OLIVEIRA, V.A. de; LUMBRERAS, J.F.; COELHO, M.R.; ALMEIDA, J.A. de; CUNHA, T.J.F.; OLIVEIRA, J.B. Sistema brasileiro de classificação de solos. 3.ed. rev. e ampl. Brasília: Embrapa, 2013a. 353p.

SANTOS, R.D. dos; LEMOS, R.C. de; SANTOS, H.G. dos; KER, J.C.; ANJOS, L.H.C. dos; SHIMIZU, S.H. Manual de descrição e coleta de solo no campo. 6.ed. rev. e ampl. Viçosa: Sociedade Brasileira de Ciência do Solo, 2013b. 100p.

SILVA, A.J.N. da; CARVALHO, F.G. de. Coesão e resistência ao cisalhamento relacionadas a atributos físicos e químicos de um Latossolo Amarelo de Tabuleiro Costeiro. Revista Brasileira de Ciência do Solo, v.31, p.853-862, 2007. DOI: 10.1590/S010006832007000500003.

SOIL MOISTURE. Guelph permeameter: operating instructions. Santa Barbara: Soil Moisture Equipment Corporation, 2012. 60p.

ZINN, Y.L.; RESCK, D.V.S.; SILVA, J.E. da. Soil organic carbon as affected by afforestation with Eucalyptus and Pinus in the Cerrado region of Brazil. Forest Ecology and Management, v.166, p.285-294, 2002. DOI: 10.1016/S0378-1127(01)00682-X.

Recebido em 31 de agosto de 2015 e aprovado em 21 de março de 2016 